\title{
Primary Oocyte
}

National Cancer Institute

\section{Source}

National Cancer Institute. Primary Oocyte. NCI Thesaurus. Code C12600.

An oocyte that is arrested in the diplotene stage of meiosis prophase 1. 